\title{
COPD assessment test and severity of airflow limitation in patients with asthma, COPD, and asthma-COPD overlap syndrome
}

This article was published in the following Dove Press journal:

International Journal of COPD

4 March 2016

Number of times this article has been viewed

\section{Kazuyoshi Kurashima \\ Yotaro Takaku \\ Chie Ohta \\ Noboru Takayanagi \\ Tsutomu Yanagisawa \\ Yutaka Sugita}

Department of Respiratory Medicine, Saitama Cardiovascular and Respiratory Center, Kumagaya, Saitama, Japan
Correspondence: Kazuyoshi Kurashima Department of Respiratory Medicine, Saitama Cardiovascular and Respiratory Center, Itai I696, Kumagaya City,

Saitama, 360-0197, Japan

$\mathrm{Tel}+8 \mid 485369900$

Fax +8I 485369920

Email kurashima.kazuyoshi@pref.saitama. lg.jp
Objective: The COPD assessment test (CAT) consists of eight nonspecific scores of quality of life. The aim of this study was to compare the health-related quality of life and severity of airflow limitation in patients with asthma, COPD, and asthma-COPD overlap syndrome (ACOS) using the CAT.

Methods: We examined CAT and lung functions in 138 patients with asthma, 99 patients with COPD, 51 patients with ACOS, and 44 patients with chronic cough as a control. The CAT score was recorded in all subjects, and the asthma control test was also administered to patients with asthma and ACOS. The CAT scores were compared, and the relationships between the scores and lung function parameters were analyzed.

Results: The total CAT scores and scores for cough, phlegm, and dyspnea were higher in patients with ACOS than in patients with asthma and COPD. The total CAT scores were correlated with the percent predicted forced expiratory volume in 1 second only in patients with COPD. The total CAT scores and dyspnea scores adjusted by the percent predicted forced expiratory volume in 1 second were higher in patients with ACOS than in patients with COPD and asthma. The CAT scores and asthma control test scores were more closely correlated in patients with ACOS than in patients with asthma.

Conclusion: Patients with ACOS have higher disease impacts and dyspnea sensation unproportional to the severity of airflow limitation.

Keywords: asthma-COPD overlap syndrome, asthma control test, ACT, COPD assessment test, CAT, quality of life, dyspnea sensation

\section{Introduction}

In adult patients with chronic respiratory symptoms, such as cough, phlegm, and dyspnea, distinguishing between asthma and COPD is sometimes difficult particularly in smokers and older adults, and a significant portion of patients with respiratory symptoms has features of both asthma and COPD called asthma-COPD overlap syndrome (ACOS). ${ }^{1-5}$ There is a broad agreement that patients with ACOS experience frequent exacerbations and a poorer quality of life than those with COPD alone. ${ }^{6-10}$ However, it is still unclear how the health-related quality of life (HRQoL) of patients with ACOS is different from that of patients with asthma and COPD and whether HRQoL and dyspnea are related to the degree of airflow limitation in patients with ACOS.

Recently, a very simple and short questionnaire (COPD assessment test [CAT] questionnaire) was developed as a valid measure to assess health status in COPD. ${ }^{11}$ The CAT and forced expiratory volume in 1 second $\left(\mathrm{FEV}_{1}\right)$ are complementary measurements for the assessment and management of COPD. ${ }^{12,13}$ The CAT score has 
been shown to be useful to identify subjects who require spirometry for the diagnosis of airflow limitation. ${ }^{14}$ In contrast to the asthma control test (ACT), which asks about asthmaspecific symptoms and reliever use, ${ }^{15}$ the CAT score consists of eight nonspecific questions about disease impacts.

The aim of this study was to compare the relationship between the CAT scores and the severity of airflow limitation in patients with asthma, COPD, and ACOS and to clarify how HRQoL of patients with ACOS is different from that of patients with asthma and COPD.

\section{Methods}

\section{Patients}

A total of 332 consecutive patients, including 138 patients with asthma, 99 patients with COPD, 51 patients with ACOS, and 44 patients with chronic cough, treated at Saitama Cardiovascular and Respiratory Center from January 23, 2015 to August 31, 2015, were enrolled in this study. Asthma was diagnosed by the history of repeated wheezing and airway reversibility at least once demonstrated by a postbronchodilator or posttreatment increase in $\mathrm{FEV}_{1}$ of $>12 \%$ and $200 \mathrm{~mL} .{ }^{16}$ COPD was diagnosed based on age $>40$ years, smoking history $\geq 20$ pack-years, a postbronchodilator $\mathrm{FEV}_{\mathrm{l}}$ / forced vital capacity $(\mathrm{FVC})<0.70$, and the differential diagnosis. ${ }^{17}$ ACOS was diagnosed when they fulfilled the diagnostic criteria for both asthma and COPD and three or more features of both diseases. ${ }^{2}$ For specialized investigations to detect features of asthma or COPD, we used high-resolution computed tomography (CT) for radiologist-diagnosed emphysema, tests for atopy, blood eosinophilia $>5 \%$, and fractional exhaled nitric oxide $>30 \mathrm{ppb}^{2}$ Persistent airflow limitation was confirmed based on at least 6 months observation period with adequate therapies and repeated spirometry in all patients with COPD and ACOS before the entry of this study. In all patients with asthma, COPD, and ACOS, the CAT scores were recorded in the stable phase at the time of spirometry. Patients exhibiting exacerbation of COPD within 1 month and patients with other comorbidities either cardiovascular, psychiatric disorders or other disorders by which study doctors considered to decrease the quality of life were excluded from the study. The ACT score was also recorded in patients with asthma and ACOS. As a control, patients who visited our clinic for examinations of chronic cough and demonstrated a normal lung function were also asked to undergo recording of the CAT scores.

The Institutional Review Board of Saitama Cardiovascular and Respiratory Center approved this study (IRB No 2015002), and all subjects provided their written informed consent prior to participation in the study.

\section{Pulmonary function tests}

The pulmonary function tests were performed using a CHESTAC8800 device (Chest M.I. Inc., Tokyo, Japan). The methods for obtaining the spirometric measurements and their predicted values were derived from the guidelines for pulmonary function tests issued by the American Thoracic Society/European Respiratory Society and Japanese Respiratory Society. ${ }^{18,19}$ Spirometry was performed before and 30 minutes after the inhalation of $200 \mu \mathrm{g}$ of salbutamol, and the data obtained after salbutamol inhalation were used for the evaluation.

\section{CAT scores}

The CAT consists of eight questions graded from 0 to 5 for cough, phlegm, chest tightness, exertional dyspnea, limited activity, confidence in leaving home, sleeplessness, and feeling of energy. Although the Japanese translation of chest tightness includes breathlessness, for this study it is expressed as chest tightness.

\section{Adjusted CAT scores}

The adjusted CAT scores for total CAT scores and exertional dyspnea scores were calculated as follows:

$$
\text { Adjusted CAT score }=\mathrm{CAT} \text { score } \times \% \mathrm{FEV}_{1} / 100
$$

The adjusted CAT score was introduced to evaluate whether the differences in CAT scores are proportional to the difference in the percent predicted $\mathrm{FEV}_{1}\left(\% \mathrm{FEV}_{1}\right)$ between different groups.

\section{Statistical analyses}

The statistical analyses were performed using the Prism 5 software program (GraphPad Software, Inc., La Jolla, CA, USA), and the data are expressed as the mean \pm SD. Spearman's rank test was used to assess the correlations. The Mann-Whitney test was used to compare parameters between two groups. Comparisons between subgroups of three or more groups were performed according to Dunn's posttest after the Kruskal-Wallis test. A $P$-value of $<0.05$ was considered to be statistically significant.

\section{Results}

\section{Clinical characteristics}

The subjects' demographics are presented in Table 1. The treatments that were used at the time of the study were also demonstrated. Patients with asthma, COPD, and ACOS entered into this study had been treated and stable, and $76.8 \%$ 
Table I Patient characteristics

\begin{tabular}{|c|c|c|c|c|c|c|}
\hline & \multirow{2}{*}{$\begin{array}{l}\text { Asthma } \\
(\mathrm{N}=138)\end{array}$} & \multirow{2}{*}{$\begin{array}{l}\text { COPD } \\
(\mathrm{N}=99)\end{array}$} & \multirow{2}{*}{$\begin{array}{l}\text { ACOS } \\
(N=5 I)\end{array}$} & \multirow{2}{*}{$\begin{array}{l}\text { Chronic } \\
\text { cough } \\
(\mathrm{N}=44)\end{array}$} & \multicolumn{2}{|l|}{$P$-value } \\
\hline & & & & & Asthma/ACOS & COPDIACOS \\
\hline Age, years & $59.7 \pm 13.3$ & $73.1 \pm 7.6$ & $68.7 \pm 9.3$ & $55.2 \pm 14.4$ & $<0.001$ & NS \\
\hline Male sex, \% & 47.1 & 92.9 & 84.3 & 36.4 & $<0.001$ & NS \\
\hline Never smoker, \% & 61.6 & 0.0 & 0.0 & 50.0 & $<0.001$ & NS \\
\hline Smoking, pack-years & $11.5 \pm 21.2$ & $68.6 \pm 35.1$ & $59.3 \pm 28.9$ & $11.9 \pm 16.6$ & $<0.001$ & NS \\
\hline CT-diagnosed emphysema, \% & 2.2 & 88.9 & 52.9 & 0.0 & $<0.001$ & $<0.001$ \\
\hline Blood eosinophil, \% & $6.8 \pm 10.9$ & $3.3 \pm 5.6$ & $6.1 \pm 7.6$ & $4.7 \pm 6.3$ & NS & NS \\
\hline $\operatorname{lgE}, \mathrm{IU} / \mathrm{mL}$ & $515.2 \pm 605.7$ & $143.2 \pm 137.2$ & $596.7 \pm 674.1$ & $|46.9 \pm| 47.7$ & NS & $<0.05$ \\
\hline FENO, ppb & $28.1 \pm 24.7$ & $17.7 \pm 12.1$ & $35.6 \pm 29.9$ & $11.5 \pm 13.1$ & NS & $<0.001$ \\
\hline \multicolumn{7}{|l|}{ Postbronchodilator } \\
\hline FVC, \% predicted & $92.1 \pm 16.1$ & $86.2 \pm 19.1$ & $81.6 \pm 16.9$ & $94.7 \pm 16.3$ & $<0.0$ I & NS \\
\hline $\mathrm{FEV}_{1}, \%$ predicted & $100.5 \pm 18.7$ & $69.6 \pm 25.5$ & $70.6 \pm 21.3$ & $110.3 \pm 16.9$ & $<0.001$ & NS \\
\hline $\mathrm{FEV}_{1} / \mathrm{FVC}, \%$ & $72.6 \pm 9.1$ & $48.7 \pm 12.7$ & $54.6 \pm 11.3$ & $82.7 \pm 8.5$ & $<0.001$ & NS \\
\hline \multicolumn{7}{|l|}{ Response to beta2-agonist } \\
\hline $\mathrm{FEV}_{1}, \%$ & $7.3 \pm 5.9$ & $5.7 \pm 6.1$ & $8.1 \pm 9.2$ & $3.3 \pm 5.4$ & NS & NS \\
\hline $\mathrm{FEV}_{1}, \mathrm{~mL}$ & $146.3 \pm \mid 22.1$ & $76.6 \pm 87.4$ & || $4.2 \pm|3| . \mid$ & $76.2 \pm 111.9$ & NS & NS \\
\hline \multicolumn{7}{|l|}{ Previously treated, \% } \\
\hline ICS use, \% & 97.8 & 41.4 & 94.1 & NA & NS & $<0.001$ \\
\hline LABA use, $\%$ & 76.1 & 55.6 & 92.2 & NA & NS & $<0.001$ \\
\hline LAMA use, $\%$ & 2.9 & 50.5 & 49.0 & NA & $<0.001$ & NS \\
\hline CAT score & $9.1 \pm 6.6$ & $10.7 \pm 6.8$ & $16.5 \pm 7.6$ & $14.9 \pm 6.9$ & $<0.001$ & $<0.001$ \\
\hline ACT score & $21.7 \pm 4.0$ & NA & $18.6 \pm 3.7$ & NA & NS & NA \\
\hline
\end{tabular}

Notes: Data are expressed as the mean \pm standard deviation unless otherwise stated. Data shown as current at the time of the study. The airway reversibility in FEV of $>12 \%$ and $200 \mathrm{~mL}$ were confirmed previously at the time of diagnosis in all patients with asthma and ACOS.

Abbreviations: ACOS, asthma-COPD overlap syndrome; ACT, asthma control test; CAT, COPD assessment test; CT, computed tomography; FENO, fractional exhaled nitric oxide; $\mathrm{FEV}_{1}$, forced expiratory volume in I second; FVC, forced vital capacity; ICS, inhaled corticosteroids; IgE, immunoglobulin E; LABA, long-acting beta2-agonist; LAMA, long-acting muscarinic antagonist; PAL, persistent airflow limitation; NA, not applicable; NS, not significant; ppb, parts per billion.

of the patients with asthma were well controlled according to the ACT score $(>19) .{ }^{15}$ The percent predicted $\mathrm{FEV}_{1}$ values were almost equal between patients with COPD and ACOS. Patients with ACOS were aged $>40$ years $(100 \%)$ and had PAL (100\%), smoking history $\geq 20$ pack-years (98.0\%), CT-diagnosed emphysema (52.9\%), the history of repeated wheezing (100\%), airway reversibility (100\%), positive for specific immunoglobulin E (29.4\%), blood eosinophilia $>5 \%(41.2 \%)$, and fractional exhaled nitric oxide $>30 \mathrm{ppb}$ $(58.8 \%)$.

\section{Baseline CAT scores}

The total CAT score was higher in patients with ACOS than in patients with asthma or COPD (Table 1). However, there were no differences between patients with asthma and patients with COPD. As shown in Figure 1, each component of CAT was not specific for COPD. The most significant component in patients with COPD was exertional dyspnea, and this score was higher than other components such as cough $(P<0.001)$, phlegm $(P<0.001)$, and chest tightness $(P<0.001)$ in patients with COPD. In patients with asthma, there were no differences among scores for cough, phlegm, and exertional dyspnea.
Patients with ACOS had higher impacts of cough, phlegm, chest tightness, exertional dyspnea, limited activity, and confidence in leaving home than patients with asthma and higher impacts of cough, phlegm, chest tightness, and exertional dyspnea than patients with COPD. In patients with ACOS, impacts for exertional dyspnea were higher than cough $(P<0.001)$, phlegm $(P<0.01)$, and chest tightness $(P<0.001)$.

\section{Relationship between CAT scores and $\%$ FEV}

The total CAT scores were well correlated with the $\% \mathrm{FEV}_{1}$ values in patients with COPD $(r=0.453, P<0.001)$, but they were not correlated in patients with asthma or ACOS (Figure 2). Table 2 shows the relationships among CAT scores and $\% \mathrm{FEV}_{1}$. Exertional dyspnea score was correlated with $\% \mathrm{FEV}_{1}$ in patients with COPD and ACOS but not in patients with asthma. The limited activity, confidence in leaving home, sleeplessness, and feeling of energy were not well correlated with $\% \mathrm{FEV}_{1}$, but they were correlated with chest tightness (or breathlessness) in all groups of asthma, COPD, and ACOS. 

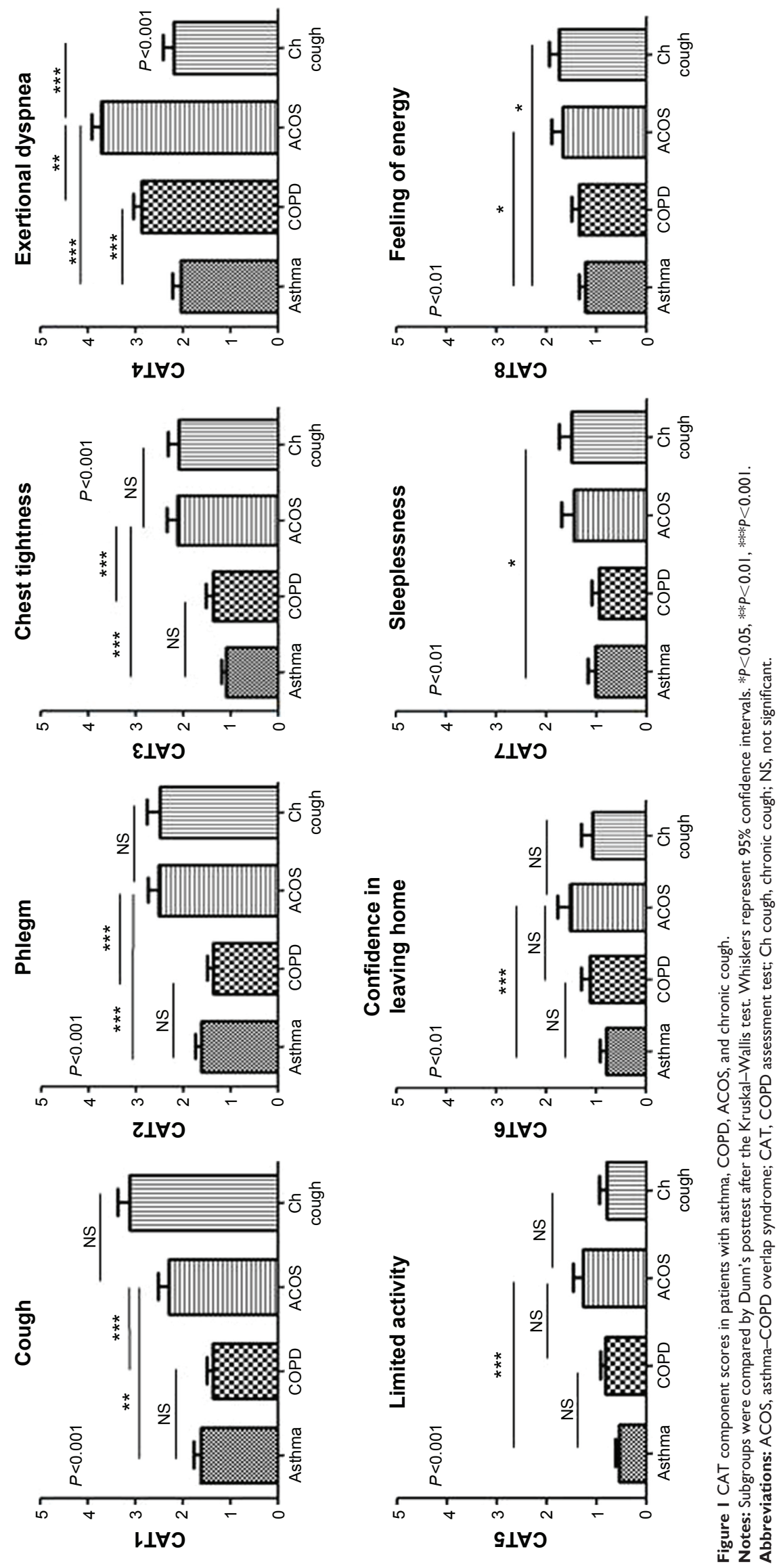

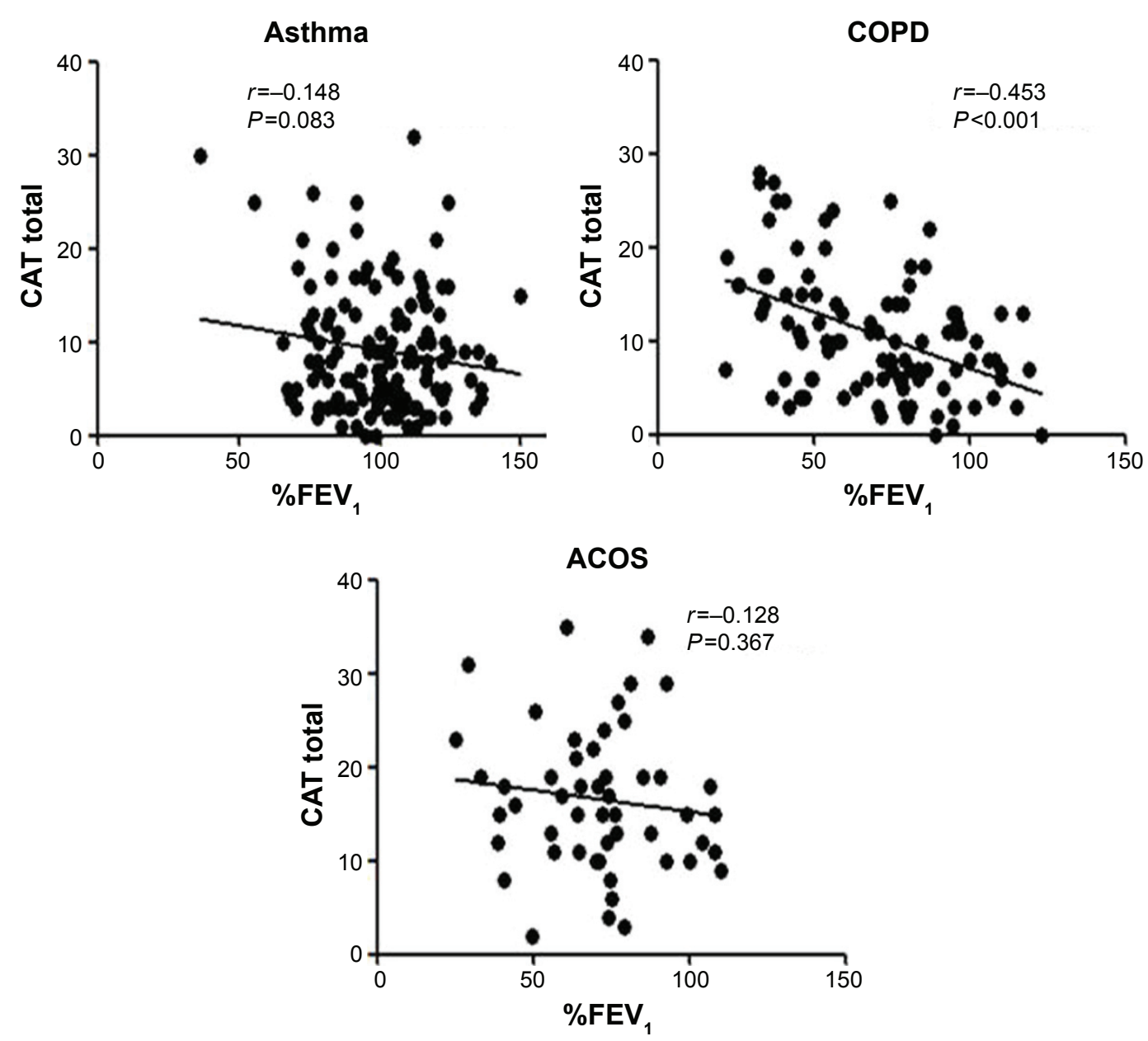

Figure 2 Relationships between the CAT scores and \%FEV, in patients with asthma, COPD, and ACOS.

Notes: The panels demonstrate the relationships between CAT total scores and \%FEV in patients with asthma (upper left panel), COPD (upper right panel), and ACOS (centre panel). Spearman's rank test was used to assess the correlations.

Abbreviations: ACOS, asthma-COPD overlap syndrome; CAT, COPD assessment test; \%FEV , percent predicted forced expiratory volume in I second.

\section{CAT scores in relation to airflow limitation}

Figure 3 shows the adjusted total CAT scores (left panel) and the adjusted exertional dyspnea scores (right panel) by $\% \mathrm{FEV}_{1}$ (original score $\times \% \mathrm{FEV}_{1} / 100$ ). There were no differences between patients with asthma and COPD in these indexes, although the indexes were significantly higher in patients with ACOS than those of asthma and COPD.

\section{Relationship between CAT and ACT scores}

In patients with asthma and ACOS, the total CAT score and the ACT score were well correlated $(r=0.633, P<0.001$; $r=0.775, P<0.001$, respectively; Figure 4). However, the CAT scores in patients with ACOS were more closely influenced by the level of asthma control than that seen in patients with asthma. Among the patients with asthma, 27.5\% of the patients with noncontrolled asthma $(\mathrm{ACT} \leq 19)$ had a low-impact level in terms of the CAT score $(<10) .{ }^{17}$ In contrast, in patients with ACOS, none of the patients with noncontrolled asthma showed a low-impact level for the CAT score ( $P=0.005$, chi-square test).

\section{Discussion}

This study showed that 1) the relationships between CAT score and $\% \mathrm{FEV}_{1}$ were different among asthma, COPD, and ACOS, and the correlation between total CAT scores and $\% \mathrm{FEV}_{1}$ was only observed in patients with $\mathrm{COPD}$; 2) patients with ACOS had higher cough, phlegm, and exertional dyspnea scores than patients with asthma or COPD, which cannot be explained by $\% \mathrm{FEV}_{1}$; and 3 ) the level of asthma control is more closely associated with the quality of life in patients with ACOS than in patients with asthma. These data suggest that patients with ACOS have higher 
Table 2 Relationships between CAT scores and FEV,

\begin{tabular}{|c|c|c|c|c|c|c|c|c|c|c|}
\hline & \multirow[t]{2}{*}{ CATI } & \multirow[t]{2}{*}{ CAT2 } & \multirow[t]{2}{*}{ CAT3 } & \multirow[t]{2}{*}{ CAT4 } & \multirow[t]{2}{*}{ CAT5 } & \multirow[t]{2}{*}{ CAT6 } & \multirow[t]{2}{*}{ CAT7 } & \multirow[t]{2}{*}{ CAT8 } & \multicolumn{2}{|c|}{$\% F E V_{1}$} \\
\hline & & & & & & & & & $r$ & $P$-value \\
\hline \multicolumn{11}{|l|}{ Asthma } \\
\hline CATI & & 0.54 & 0.55 & 0.41 & 0.34 & 0.35 & 0.42 & 0.51 & -0.09 & $0.28 \mathrm{I}$ \\
\hline CAT2 & 0.54 & & 0.47 & 0.30 & 0.42 & 0.31 & 0.37 & 0.28 & 0.02 & 0.776 \\
\hline CAT3 & 0.55 & 0.47 & & 0.52 & 0.58 & 0.59 & 0.55 & 0.57 & -0.13 & 0.129 \\
\hline CAT4 & $0.4 I$ & 0.30 & 0.52 & & 0.42 & 0.31 & 0.30 & 0.46 & -0.11 & 0.184 \\
\hline CAT5 & 0.34 & 0.42 & 0.58 & 0.42 & & 0.69 & 0.51 & 0.52 & 0.04 & 0.663 \\
\hline CAT6 & 0.35 & 0.31 & 0.59 & 0.31 & 0.69 & & 0.61 & 0.64 & -0.09 & 0.299 \\
\hline CAT7 & 0.42 & 0.37 & 0.55 & 0.30 & 0.51 & 0.61 & & 0.60 & -0.05 & 0.589 \\
\hline CAT8 & 0.51 & 0.28 & 0.57 & 0.46 & 0.52 & 0.64 & 0.60 & & -0.10 & 0.264 \\
\hline \multicolumn{11}{|l|}{ COPD } \\
\hline CATI & & 0.54 & 0.51 & 0.38 & 0.32 & 0.38 & 0.35 & $0.4 I$ & -0.18 & 0.083 \\
\hline CAT2 & 0.54 & & 0.45 & 0.22 & 0.32 & 0.30 & 0.30 & 0.28 & -0.16 & 0.115 \\
\hline CAT3 & $0.5 I$ & 0.45 & & 0.69 & 0.52 & 0.63 & 0.42 & 0.57 & -0.44 & $<0.001$ \\
\hline CAT4 & 0.38 & 0.22 & 0.69 & & 0.49 & 0.57 & 0.36 & 0.46 & -0.54 & $<0.001$ \\
\hline CAT5 & 0.32 & 0.32 & 0.52 & 0.49 & & 0.72 & 0.42 & 0.44 & -0.24 & 0.016 \\
\hline CAT6 & 0.38 & 0.30 & 0.63 & 0.57 & 0.72 & & 0.47 & 0.56 & -0.32 & 0.001 \\
\hline CAT7 & 0.35 & 0.30 & 0.42 & 0.36 & 0.42 & 0.47 & & 0.61 & -0.24 & 0.019 \\
\hline CAT8 & 0.41 & 0.28 & 0.57 & 0.46 & 0.44 & 0.56 & 0.61 & & -0.33 & 0.001 \\
\hline \multicolumn{11}{|l|}{ ACOS } \\
\hline CATI & & 0.64 & 0.51 & 0.41 & 0.37 & 0.26 & 0.29 & 0.30 & -0.04 & 0.777 \\
\hline CAT2 & 0.64 & & 0.44 & 0.33 & 0.36 & 0.38 & 0.17 & 0.28 & 0.17 & 0.238 \\
\hline CAT3 & 0.51 & 0.44 & & 0.63 & 0.57 & 0.63 & 0.48 & 0.64 & -0.15 & 0.297 \\
\hline CAT4 & 0.41 & 0.33 & 0.63 & & $0.4 I$ & 0.48 & 0.36 & 0.56 & -0.34 & 0.013 \\
\hline CAT5 & 0.37 & 0.36 & 0.57 & 0.41 & & 0.78 & 0.44 & 0.62 & -0.13 & 0.378 \\
\hline CAT6 & 0.26 & 0.38 & 0.63 & 0.48 & 0.78 & & 0.38 & 0.58 & -0.15 & 0.288 \\
\hline CAT7 & 0.29 & 0.17 & 0.48 & 0.36 & 0.44 & 0.38 & & 0.63 & 0.16 & 0.260 \\
\hline CAT8 & 0.30 & 0.28 & 0.64 & 0.56 & 0.62 & 0.58 & 0.63 & & -0.03 & 0.826 \\
\hline
\end{tabular}

Note: Correlation coefficient among CAT scores and between CAT scores and \%FEV, are shown.

Abbreviations: ACOS, asthma-COPD overlap syndrome; CAT, COPD assessment test; CATI, cough; CAT2, phlegm; CAT3, chest tightness; CAT4, exertional dyspnea; CAT5, limited activity; CAT6, confidence in leaving home; CAT7, sleeplessness; CAT8, feeling of energy; \%FEV ${ }_{1}$, percent predicted forced expiratory volume in I second; $r$, coefficient.
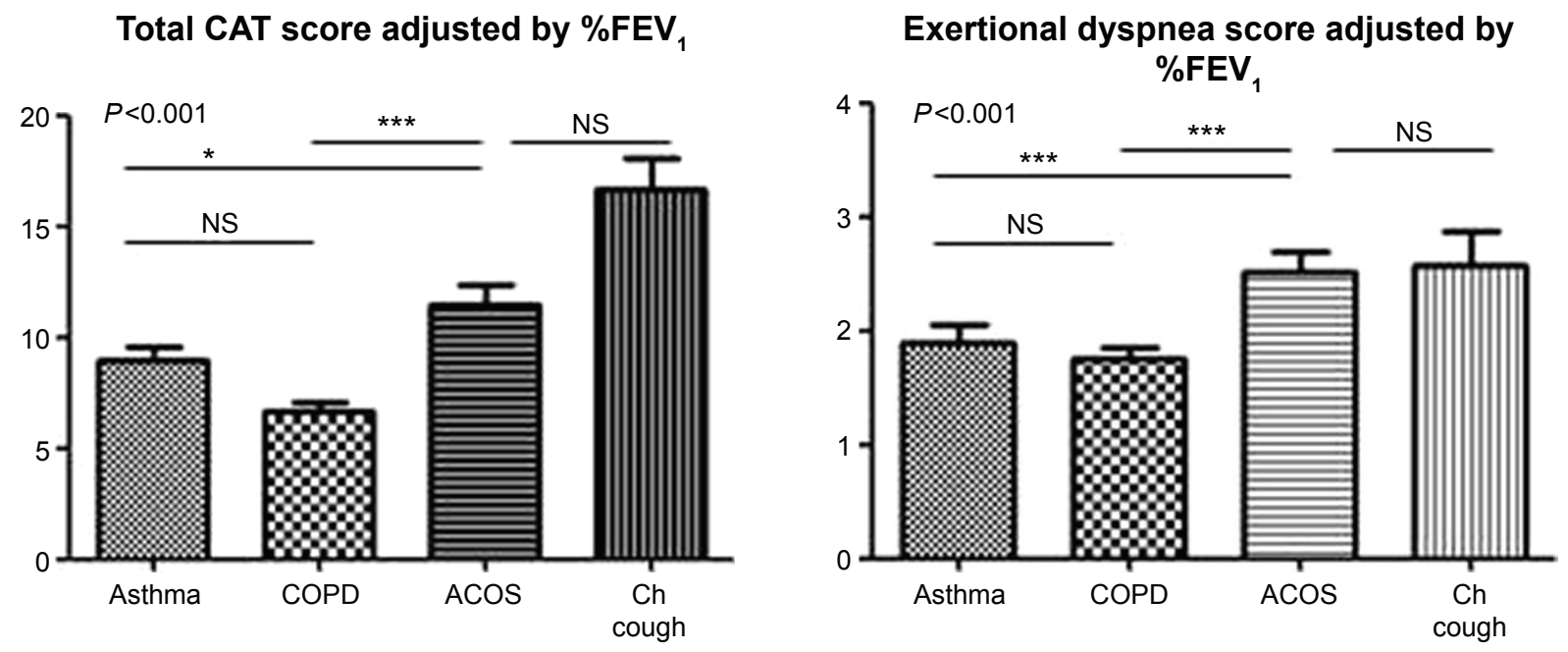

Figure 3 Total CAT scores and exertional dyspnea scores adjusted by \%FEV, in patients with asthma, COPD, ACOS, and chronic cough.

Notes: The adjusted CAT scores for total CAT scores and exertional dyspnea scores were calculated as follows: Adjusted CAT score $=($ CAT score $) \times \%$ FEV $/ / 00$. The adjusted score was introduced to evaluate the impacts of CAT scores in relation to the severity of airflow limitation. Whiskers represent $95 \%$ confidence intervals. NS denotes not significant, $* P<0.05$, $* * * P<0.001$.

Abbreviations: ACOS, asthma-COPD overlap syndrome; CAT, COPD assessment test; $C$ cough, chronic cough; \%FEV ${ }_{1}$, percent predicted forced expiratory volume in I second. 

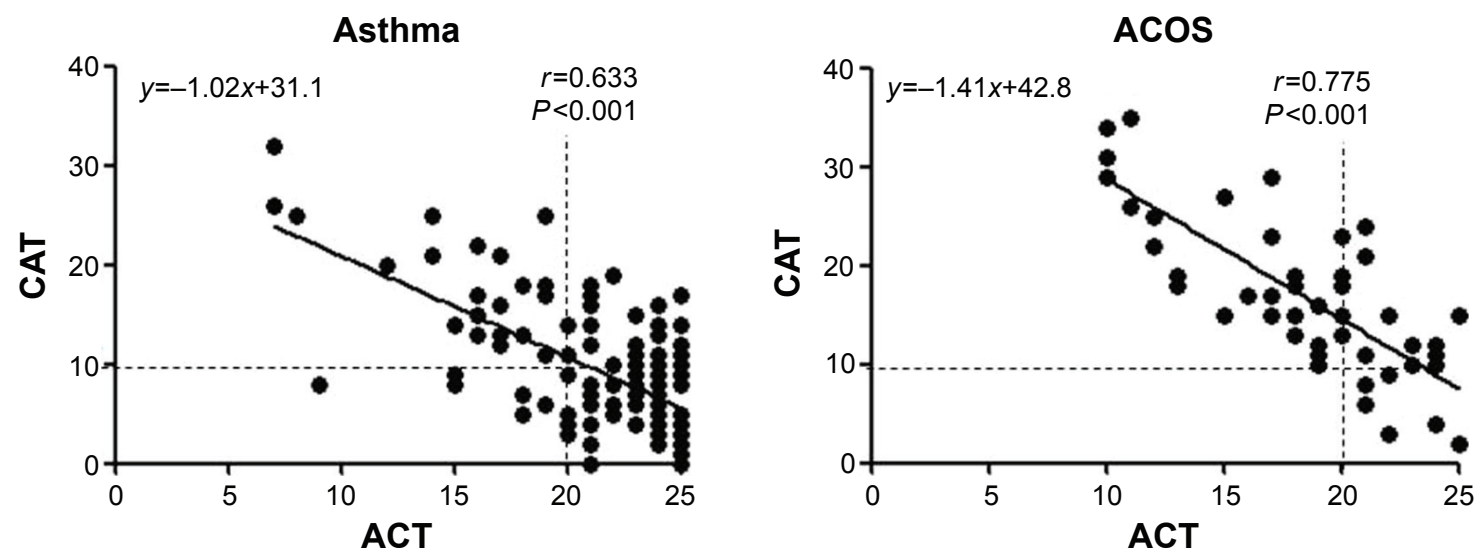

Figure 4 Relationships between the CAT scores and ACT scores in patients with asthma and ACOS.

Notes: The panels demonstrate relationships between CAT total scores and ACT scores in patients with asthma (left panel) and ACOS (right panel). Spearman's rank test was used to assess the correlations. Dotted lines indicate low-impact levels based on the CAT $(<10)$ scores and well-controlled levels on ACT $(>I 9)$ scores. Abbreviations: ACOS, asthma-COPD overlap syndrome; ACT, asthma control test; CAT, COPD assessment test.

disease impacts and dyspnea sensation unproportional to the severity of airflow limitation, and asthma control is more important in patients with ACOS.

The impaired HRQoL in patients with ACOS is well documented in previous studies, ${ }^{6-10}$ but this study assessed the CAT scores and the ACT scores in patients with asthma, COPD, and ACOS at the same time. The CAT is widely used in primary practice so that the knowledge about the individual features of the CAT components in patients with asthma, COPD, ACOS, and other nonspecific cough might be useful for clinicians. In the assessment of CAT, a score of two is the most consistent minimum important difference (MID) for the clinical outcome, whereas a score of 3 is the most consistent MID in the assessment of ACT..$^{20,21}$ The relationships between the CAT and the ACT scores in patients with asthma and ACOS are simple, but the results were rather unexpected to us. In patients with asthma, the asthma control level was not strongly associated with the HRQoL. In fact, some of the patients with uncontrolled asthma did not feel significantly poor quality of life. In contrast, asthma control level was closely associated with the level of quality of life in patients with ACOS.

Several studies have reported the CAT scores as a screening tool for COPD in a general population. ${ }^{14,22}$ However, this study showed that the elevated CAT scores are not disease specific, but the patterns of elevated CAT components might be more useful to characterize these diseases. Elevated exertional dyspnea score compared to other components was observed in patients with COPD and ACOS, suggesting the presence of persistent airflow limitation. In patients with chronic cough or asthma, this score was also elevated but not significantly higher than cough and phlegm components.
Elevated cough and phlegm scores in addition to exertional dyspnea score were more often observed in patients with ACOS than in patients with COPD.

The higher total CAT score and exertional dyspnea score noted in patients with ACOS compared to those of patients with asthma and COPD cannot be explained by the severity of airflow limitation. The $\% \mathrm{FEV}_{1}$ values of patients with ACOS were similar to those of patients with COPD. These scores adjusted by $\% \mathrm{FEV}_{1}$ were higher in patients with ACOS but similar in patients with asthma and COPD. The findings suggest that patients with ACOS have more impaired quality of life and dyspnea sensation unproportional to the level of $\% \mathrm{FEV}_{1}$ compared to the cases of asthma or COPD.

Although the pattern of elevated CAT components was different among the patients with asthma, COPD, and ACOS, there were similarities in the relationships among CAT scores in these groups. For example, "sleeplessness" and "feeling of energy" were closely correlated in all groups. Of note, "limited activity," "confidence in leaving home," "sleeplessness, and feeling of energy" were more closely correlated with "chest tightness" than with "exertional dyspnea." It suggests that uncomfortable chest sensation at rest is associated with the limited activity and the poor health feeling in all patients.

There are several limitations associated with this study. One of the CAT components "chest tightness" contains the meaning of "breathlessness" in Japanese, ${ }^{23}$ although we considered the effects of the translation into Japanese might be minimum with regard to the results of this study. The patients with asthma, COPD, and ACOS were stable and already under treatment. Hence, the results might be different 
for untreated and unstable patients. The postbronchodilator $\mathrm{FEV}_{1} / \mathrm{FVC}<0.7$ cutoff ratio might overestimate airway obstruction, but we confirmed persistent airflow limitation and clinical courses in COPD and ACOS during a substantial period before the entry of patients into the study, with appropriate therapies according to the guidelines. ${ }^{16,17}$ Depression and anxiety may influence the HRQoL in COPD and asthma. ${ }^{24,25}$ We excluded the patients who had history or symptoms of depression and anxiety, but no psychiatric tests were performed. Finally, the patients with chronic cough were a heterogeneous group and this condition was not classified as a single clinical entity. However, their lung function parameters and CT findings were normal, and cases of clinical asthma were excluded.

\section{Conclusion}

In conclusion, patients with overlap syndrome suffer more impaired quality of life and exertional dyspnea than patients with asthma or COPD if their airflow limitations are similar. However, the results also suggest that patients with ACOS have more chances to be treated at an early stage of airflow limitation. In addition, more direct improvement of HRQoL can be expected in patients with ACOS with their asthma control. Suzuki et al recently reported that budesonide/ formoterol therapy increased the $\mathrm{FEV}_{1}$ values and decreased airway wall thickness in patients with ACOS. ${ }^{26}$ Therefore, recognizing ACOS is important for clinicians in primary care, and the pattern of CAT scores might be helpful in the screening of ACOS.

\section{Acknowledgment}

We wish to thank the medical staff of Saitama Cardiovascular and Respiratory Center who cared for the patients.

\section{Author contributions}

All authors contributed toward data acquisition, data analysis, drafting and critically revising the paper and agree to be accountable for all aspects of the work.

\section{Disclosure}

The authors report no conflicts of interest in this work.

\section{References}

1. Silva GE, Sherrill DL, Guerra S, Barbee RA. Asthma as a risk factor for COPD in a longitudinal study. Chest. 2004;126:59-65.

2. Diagnosis of Diseases of Chronic Airflow Limitation: Asthma COPD and Asthma-COPD Overlap Syndrome (ACOS), 2014. Available from: http:// www.goldcopd.org/Guidelines/asthma-copd-overlap.html. Accessed January 10, 2015.
3. Gibson PG, Simpson JL. The overlap syndrome of asthma and COPD: what are its features and how important is it? Thorax. 2009;64: 728-735.

4. Abramson MJ, Schattner RL, Sulaiman ND, Del Colle EA, Aroni R, Thien F. Accuracy of asthma and COPD diagnosis in Australian general practice: a mixed methods study. Prim Care Respir J. 2012;21: 167-173.

5. Soler-Cataluña JJ, Cosío B, Izquierdo JL, et al. Consensus document on the overlap phenotype COPD-asthma in COPD. Arch Bronconeumol. 2012;48:331-337.

6. Kauppi $\mathrm{P}$, Kupiainen H, Lindqvist A, et al. Overlap syndrome of asthma and COPD predicts low quality of life. J Asthma. 2011;48:279-285.

7. Miravitles M, Soriano JB, Ancochea J, et al. Characterization of the overlap COPD-asthma phenotype. Focus on physical activity and health status. Respir Med. 2013;107:1053-1060.

8. Rhee CK, Yoon HK, Yoo KH, et al. Medical utilization and cost in patients with overlap syndrome of chronic obstructive pulmonary disease and asthma. COPD. 2014;11:163-170.

9. Menezes AMB, de Oca MM, Pérez-Padilla R, et al; PLATINO Team. Increased risk of exacerbation and hospitalization in subjects with an overlap phenotype COPD-asthma. Chest. 2014;145:297-304.

10. Hardin M, Cho M, McDonald ML, et al. The clinical and genetic features of the COPD asthma overlap syndrome. Eur Respir J. 2014; 44:341-350.

11. Jones PW, Harding G, Berry P, Wiklund I, Chen WH, Kline Leidy N. Development and first validation of the COPD assessment test. Eur Respir J. 2009;34:648-654.

12. Jones PW, Brusselle G, Dal Negro RW, et al. Properties of the COPD assessment test in a cross-sectional European study. Eur Respir J. 2011;38:29-35.

13. Ghobadi H, Ahari SS, Kameli A, Lari SM. The relationship between COPD assessment test (CAT) scores and severity of airflow obstruction in stable COPD patients. Tanaffos. 2012;11:22-26.

14. Yoshimoto D, Nakano Y, Onishi K, Hagan G, Jones P. The relationship between the COPD assessment test score and airflow limitation in Japan in patients aged over 40 years with a smoking history. Int J Chron Obstruct Pulmon Dis. 2014;9:1357-1363.

15. American Thoracic Society [webpage on the Internet]. Asthma Control Test. Available from: http://www.thoracic.org/members/assemblies/ assemblies/srn/questionaires/act.php. Accessed January 10, 2015.

16. Global Initiative for Asthma [homepage on the Internet]. Global Strategy for Asthma Management and Prevention; 2014. Available from: http:// www.ginasthma.org/. Accessed January 10, 2015.

17. Global Initiative for Chronic Obstructive Lung Disease [homepage on the Internet]. 2014. Available from: http://www.goldcopd.org/. Accessed January 10, 2015.

18. Miller MR, Hankinson J, Brusasco V, et al. Standardisation of spirometry. Eur Respir J. 2005;26:319-338.

19. Japanese Respiratory Society. The predicted values of spirometry and arterial blood gas analysis in Japanese. J Jpn Resp Soc. 2001;39:1-17. Japanese.

20. Kon SSC, Canavan JL, Jones SE, et al. Minimum clinically important difference for the COPD assessment test: a prospective analysis. Lancet Respir Med. 2014;2:195-203.

21. Schatz M, Kosinski M, Yarlas AS, et al. The minimally important difference of the asthma control test. J Allergy Clin Immunol. 2009;124: 719-723.

22. Raghaven N, Lam YM, Webb KA, et al. Components of the COPD assessment test (CAT) associated with a diagnosis of COPD in a random population sample. COPD. 2012;9:175-183.

23. The Japanese Respiratory Society. Fourth Edition of the Japanese Respiratory Society COPD Guideline for Diagnosis and Treatment. Tokyo: The Japanese Respiratory Society; 2013. Japanese.

24. Blakemore A, Chris D, Guthrie E, et al. Depression and anxiety predict health-related quality of life in chronic obstructive pulmonary disease: systematic review and meta-analysis. Int J Chron Obstruct Pulmon Dis. 2014;9:501-512. 
25. Yonas MA, Marsland AL, Emeremni CA, Moore CG, Holguin F, Wenzel S. Depressive symptomatology, quality of life and disease control among individuals with well-characterized severe asthma. J Asthma. 2013;50:884-890.
26. Suzuki T, Tada Y, Kawata N, et al. Clinical, physiological, and radiological features of asthma-chronic obstructive pulmonary disease overlap syndrome. Int J Chron Obstruct Pulmon Dis. 2015;10:947-954.

International Journal of COPD

\section{Publish your work in this journal}

The International Journal of COPD is an international, peer-reviewed journal of therapeutics and pharmacology focusing on concise rapid reporting of clinical studies and reviews in COPD. Special focus is given to the pathophysiological processes underlying the disease, intervention programs, patient focused education, and self management protocols.
Dovepress

This journal is indexed on PubMed Central, MedLine and CAS. The manuscript management system is completely online and includes a very quick and fair peer-review system, which is all easy to use. Visit $\mathrm{http}: / / \mathrm{www}$.dovepress.com/testimonials.php to read real quotes from published authors.

Submit your manuscript here: http://www.dovepress.com/international-journal-of-chronic-obstructive-pulmonary-disease-journal 